\title{
Radiological anatomy of distal phalanx of front foot in the pure Iranian Arabian horse
}

\author{
D. Vosugh1, M.N. Nazem², A.R. Hooshmand ${ }^{3}$ \\ ${ }^{1}$ Department of Radiology, School of Veterinary Medicine, Shahid Bahonar University of Kerman, Kerman, Iran \\ 2Department of Basic Science, School of Veterinary Medicine, Shahid Bahonar University of Kerman, Kerman, Iran \\ ${ }^{3}$ Post Graduate Student, School of Veterinary Medicine, Shahid Bahonar University of Kerman, Kerman, Iran
}

[Received: 21 December 2016; Accepted: 16 February 2017]

Background: Among the different breeds of horses, Asil horses with a five thousand year history have played an important role in human life. This study was designed as a result of the lack of information about the normal radiographic anatomy of this breed.

Materials and methods: Radiography of the distal phalanx and associated soft-tissue structures of the front feet of 10 healthy pure Iranian Arabian horses was performed on lateromedial radiographic projection to determine normal radiographic morphometry of this part. There were no problems in their limbs and in their history.

Results: Obtained radiograph of each front distal phalanx was used to measure important distances, angles and ratios of the hoof wall. There was no significant difference between left and right digits for any radiographic determination.

Conclusions: Measurements of this study differed from those reported in other breeds, so it can be used in the future as reference values for diagnosis of laminitis in front feet of Iranian Arabian horses. (Folia Morphol 2017; 76, 4: 702-708)

Key words: Iranian Arabian horse, distal phalanx, radiographic anatomy

\section{INTRODUCTION}

The Asil horse of Iran, which is known in the west as the Arab, is labelled by the name of the region from which it comes, mostly to avoid confusion with other breeds of a somewhat Arab type.

Accurate diagnosis of anatomical change is dependent on a priori knowledge of normality [19]. Anatomical changes compromise the normal biomechanics of the foot and can lead to secondary digital pathologies and alterations in hoof horn production which change the shape of the hoof capsule. These events collectively cause stance and gait alterations and/or chronic and acute foot pain [6].
The degree of anatomical change within a laminitic foot varies considerably between individuals, ranging from mild to severe. This is of clinical importance because treatment outcome and recovery prospects are related to the degree of anatomical change [10]. Clinical assessment of the presented foot should therefore be directed to the effective detection and quantification of anatomical change. So effective methods of diagnosis of anatomical change are essential to ensure that veterinary and farriery intervention occurs at an early stage, when the prospects of treatment success and recovery are most favourable [6].

Address for correspondence: Dr. D. Vosugh, Associate Professor of Radiology, Department of Clinical Sciences, School of Veterinary Medicine, Shahid Bahonar University of Kerman, Pazhuhesh Square, Kerman, Iran, P.O. Box: 76169133, tel: +983431322911, fax: +983433257447, e-mail: dvosugh@yahoo.com; nnazem@uk.ac.ir 
Modest anatomical change does not result in discernible changes in hoof capsule shape [27] and clinical signs of pain are often absent until advanced stages of anatomical change [6]. Hence, radiographic assessment of the laminitic horse foot is of primary diagnostic importance and a lateromedial radiograph represents the 'gold standard' for diagnosis of anatomical change [29].

Objective methods are necessary to ensure accurate diagnosis. Hence, there is a need to define the normal radiological anatomy of the foot. With normative data established, the nature and extent of change can be assessed within laminitic feet. This requires evaluation of an appropriate series of radiological parameters that define the foot anatomy and identify anatomical changes associated with laminitis [6]. Therefore, understanding the normal radiographic findings of the foot is necessary.

Many authors have described the normal radiographic anatomy of the front feet of normal horses. Bushe et al. [3] have mentioned the relation between the third phalanx angle and coffin angle in sound horses. Qualitative and morphometric radiographic findings in the distal phalanx (DP) and digital soft tissue of sound and footsore Thoroughbreds were compared by Linford [19]. They have also qualified DP and digital soft tissue findings of sound Thoroughbred racehorses and matched the data with their racing performance. Cripps and Eustace [9] have measured the normal radiographic findings in the feet of normal horses with relevance to laminitis.

On the other hand, a wide range of anatomical changes has been described in laminitic feet. This has been reviewed in detail elsewhere by Herthel and Hood [14] and Parks and Mair [25]. Collins et al. [8] highlighted anatomical differences between the donkey and horse throughout the distal limb and questioned the validity of applying this model without corroborating data. In another study, they indicated that significant changes to the hoof, bone alignments and interrelationships and to the morphology of the DP occur within laminitic donkey feet [6].

Although the radiographic appearance of the normal foot must be understood to recognise subtle abnormalities [28], there is little information about the radiological anatomy of normal hoof and digital soft tissues of pure Iranian Arabian horse. So the purpose of the study reported here was to determine a normal radiographic appearance and morphometry of the DP and its related soft tissue in mature pure Iranian Arabian horses without any clinical signs of lameness and foot problems.

\section{MATERIALS AND METHODS}

All procedures involving the experimental use of animals were approved by the Animal Ethics Committee, a branch of the Research Council of the Veterinary School in Shahid Bahonar University, Kerman Province, Iran.

A total of 10 healthy pure Iranian Arabian horses (10 mares) ranging in age from 4 to 9 years old and with a height (measured at the highest point of the withers) between 157 and $162 \mathrm{~cm}$ were included in this study. All the horses had their own history and certificates. They had the same diet and training management and also the same farrier. There was no history of lameness and limb abnormality in their life. Each horse was observed trotting in circles to the left and right, and walking and trotting in a straight line.

\section{Radiographic protocol}

Radiographs were made using a portable $40 \mathrm{~mA}$, $80 \mathrm{kV}$ X-ray generator with variable timer. Care was taken to ensure straight lateromedial projections without obliquity by aligning the radiographic beam so that it passed perpendicularly to the sagittal plane through the foot while being centred in the middle of the hoof $3 \mathrm{~cm}$ proximal to the bearing surface. The hoof was also placed on an $8 \mathrm{~cm}$ thick wooden block so that the distance of the centre of the beam to ground surface was about $10 \mathrm{~cm}$. To differentiate the bearing surface from the block a metal bar was placed on the block surface. The focus-film distance for each projection was $75 \mathrm{~cm}$. All horseshoes were removed and the frog sulci and the sole surface of the digits were cleaned prior to radiography. A layer of barium sulphate contrast agent with proper concentration was rubbed on the dorsal surface of hoof wall, sole surface, and frog sulci for better visualisation of these parts on the radiographs. A metal marker was positioned at the palpable proximal limit of the hoof wall. This enabled radiographic calibration (to account for any magnification effects) and discrimination of both the dorsal aspect and proximal limit of the hoof wall. All the measurements from lateromedial radiographs were multiplied using the magnification correction factor to gain the actual distances $[6,20,31]$. 


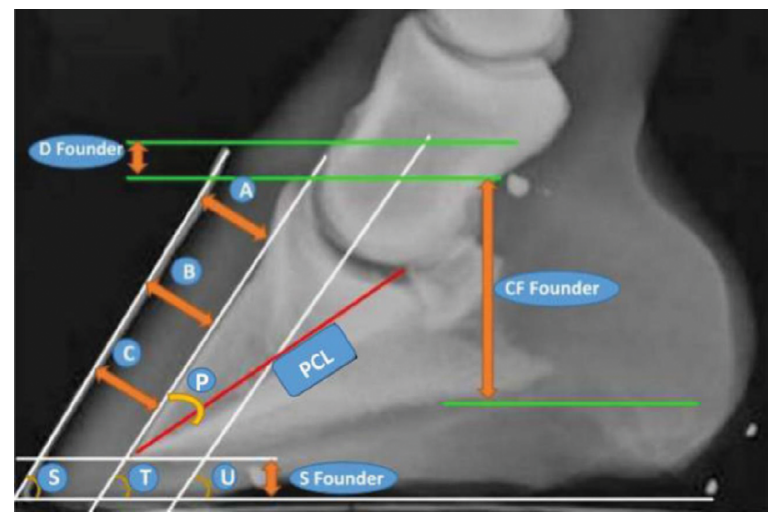

Figure 1. Picture to show how the various radiographic measurements were made; $A, B, C$ - hoof wall thickness in proximal, middle and distal (respectively) of the hoof; $\mathrm{PCL}$ - palmarocortical length; $\mathrm{P}$ - caudal angle formed between a line through the palmarocortical and a line through dorsal surface of the distal phalanx; $\mathrm{S}$ - the caudal angle formed between a line along the dorsal surface of the hoof wall and a line along the bearing surface of the hoof; $\mathrm{T}$ - the caudal angle formed between a line along the dorsal cortex of the phalanx and a line along the bearing surface of the hoof wall; $\mathrm{U}$ - the caudal angle formed between a line through the central axis of the middle phalanx and a line along the bearing surface of the hoof wall.

\section{Morphometric analysis of the radiographs}

In each obtained radiograph, 7 distances, 6 angles, and 3 ratios of the DP and the hoof wall were measured. The morphometric assessments were made as follows:

1. The hoof wall and its soft tissue thickness included three regions:

a) Total soft tissue thickness dorsal to the distal aspect of the DP (STTD) (Fig. 1A);

b) Total soft tissue thickness dorsal to the middle aspect of the DP (STTM) (Fig. 1B);

c) Total soft tissue thickness dorsal to the proximal aspect of the DP (STTP) (Fig. 1C).

They were the shortest distance between the dorsal surface of the hoof wall and the dorsal cortex of DP.

2. Palmarocortical length $(P C L)$ of the DP: The distance between the tip of the solar margin and the distal end of the phalangonavicular joint (Fig. 1).

3. The ratios of the wall thickness to the PCL: These ratios were assessed by proper thickness of STTD, STTM, and STTP expressed as percentage.

4. Hoof wall axis (S-angle): The caudal angle formed between a line along the dorsal surface of the hoof wall and a line along the bearing surface of the hoof (Fig. 1).
5. Distal phalanx axis (T-angle): The caudal angle formed between a line along the dorsal cortex of the phalanx and a line along the bearing surface of the hoof wall (Fig. 1).

6. The difference between $\mathrm{S}$ - and T-angle (H-angle).

7. Middle phalanx axis (U-angle): The caudal angle formed between a line through the central axis of the middle phalanx and a line along the bearing surface of the hoof wall (Fig. 1).

8. The difference between $\mathrm{U}$ - and T-angle (R-angle).

9. D-founder: The perpendicular distance from the horizontal line through the extensor process to the horizontal line through the coronary band (Fig. 1).

10.S-founder: The perpendicular distance from the horizontal line through the highest point of the sole surface which was robbed by contrast agent (barium sulphate) in front of the frog to the tip of the DP (Fig. 1).

11. CF-founder: The perpendicular distance from the horizontal line through the top point of the frog corium to the extensor process (Fig. 1).

12. P-angle: A caudal angle formed between a line through the palmarocortical and a line through dorsal surface of the DP (Fig. 1) [9, 20, 31].

\section{Statistical evaluation}

All the obtained data were expressed as mean \pm standard error. The average and standard error were determined as standard measurements in pure Iranian Arabian horses. On the other hand, data were analysed by paired t-test followed by Tukey's test, using the software SPSS 16 (Statistical Package for the Social Sciences, version 16, SPSS; Chicago, USA). P-values less than 0.05 were considered statistically significant.

\section{RESULTS}

The results of this study are summarised in Tables 1 and 2. Measurements of lateromedial radiographs were distances, ratios, and angles of morphometric variables of DP and hoof in total, left and right of morphometric variables in front feet in pure Iranian Arabian horses.

In this research, there was no statistically significant difference $(p>0.05)$ in measured parameters between the left and right forelimb radiographs.

\section{DISCUSSION}

Laminitis is a debilitating foot disorder that results in irreversible anatomical change within a foot fol- 
Table 1. Morphometric characteristics and measurement of radiological parameters for the foot and of the distal phalanx (measurements are based on $\mathrm{mm}$ ); mean \pm standard error

\begin{tabular}{lccc}
\hline Parameter & Total measurement & Left forefoot & Right forefoot \\
\hline STTD & $17.3 \pm 0.56$ & $17.1 \pm 0.54$ & $17.5 \pm 0.59$ \\
STTM & $18.1 \pm 0.36$ & $18.3 \pm 0.46$ & $18 \pm 0.27$ \\
STTP & $18.1 \pm 0.13$ & $18.5 \pm 0.11$ & $17.8 \pm 0.15$ \\
PCL & $64.7 \pm 1.32$ & $64.4 \pm 0.46$ & $65.1 \pm 2.18$ \\
STTD/PCL (\%) & $26.3 \pm 0.9$ & $26.2 \pm 0.63$ & $26.5 \pm 1.17$ \\
STTM/PCL & $27.6 \pm 0.75$ & $28.1 \pm 0.73$ & $27.2 \pm 0.78$ \\
STTP/PCL & $27.5 \pm 0.65$ & $28.1 \pm 0.31$ & $26.9 \pm 0.99$ \\
D-founder & $6.2 \pm 0.43$ & $6.6 \pm 0.37$ & $5.8 \pm 0.49$ \\
S-founder & $10.4 \pm 0.36$ & $10.3 \pm 0.37$ & $10.5 \pm 0.35$ \\
CF-founder & $47.6 \pm 1.45$ & $48.7 \pm 0.61$ & $46.6 \pm 2.29$ \\
\hline
\end{tabular}

Abbreviations - see text

Table 2. Summary of the angular and linear radiographic parameters of the front feet (measurements are based on degree); mean \pm standard error

\begin{tabular}{lccc}
\hline Parameter & Total measurement & Left forefoot & Right forefoot \\
\hline S-angle & $49.6 \pm 1.71$ & $49.2 \pm 1.65$ & $49.9 \pm 1.78$ \\
T-angle & $49.4 \pm 1.34$ & $49.2 \pm 1.14$ & $49.6 \pm 1.54$ \\
H-angle & $-0.2 \pm 1.45$ & $2 \pm 1.47$ & $2.6 \pm 1.44$ \\
U-angle & $56.6 \pm 0.54$ & $56.6 \pm 0.62$ & $56.6 \pm 0.46$ \\
R-angle & $7.2 \pm 1.56$ & $7.3 \pm 1.52$ & $6.9 \pm 1.61$ \\
P-angle & $33.8 \pm 0.59$ & $33.9 \pm 0.63$ & $33.7 \pm 0.55$ \\
\hline
\end{tabular}

Abbreviations - see text

lowing failure of the suspensory apparatus of the DP $[7,29]$. This problem is one of the most common causes of lameness in horses. Laminae are the structures which attach the pedal bone to the inside of the hoof wall; if these laminae become inflamed or damaged they can cause severe pain and distress. With the occurrence of laminitis some of the laminae die off, which results in an unstable foot. The pedal bone may then rotate within the foot, or in more severe cases the pedal bone may sink within the foot [29]. Some studies showed that anatomical change is defined as changes of the internal relationships of the osseous structures of the foot and their relationship with the hoof capsule and/or changes of the morphometric characteristics of the DP. Most frequently, laminitis will occur in both front feet, which is logical given that horses bear approximately $60 \%$ of their weight on their front limbs [15].
Anatomical change within the laminitis is characterised by significant increases in angular deviation between the dorsal aspect of the DP and dorsum of the hoof wall and phalangeal rotation and increase in distal displacement of the DP [6].

The goal of farriers and equine clinicians is to achieve a dorsopalmar foot balance in which the hoof-paster axis is straight; i.e. the dorsal hoof wall is parallel to the dorsal surface of the pastern region $[23,24]$ and the horn tubules at the heels are at a similar angle to those at the dorsal hoof wall [1]. In a broken-back, long-toe/low-heel conformation, the dorsal hoof angle is smaller than that of the pastern. In many of these horses the heels are weakened and the horn tubules in the heel region bend and their angle relative to the ground is decreased, resulting in the heels sinking and becoming under-run, termed collapsed heels [5]. It has been suggested that this 
change in conformation increases the load on the palmar aspect of the foot during weight bearing [24], producing biomechanical changes including permanent extension of the distal interphalangeal joint and decreased angle of deviation of the deep digital flexor tendon (DDFT) around the navicular bone. Furthermore, some authors contend that these changes increase the force exerted by the DDFT on the navicular bone predisposing horses to navicular disease [3, 23, 33].

It is generally accepted that radiological assessment of a laminitic foot is of clinical importance in confirming a diagnosis of anatomical changes within the foot of the affected animal, thereby confirming progression into the chronic phase of the disease and determining the nature and extent of these changes within the foot [6].

Adoption of a multiparameter approach to the radiological assessment of the foot provides the clinician with a more complete understanding of the internal anatomy of the presented foot and gives objective evidence of anatomical change associated with laminitis [6]. The lateromedial radiographic view represents the 'gold standard' from which diagnosis and prognostic assessment are routinely achieved [14]. Lateromedial radiographs should be taken at the first sign of acute laminitis to develop a baseline for continuous radiographic comparison. Early radiographic signs in laminitis include mild bony reaction along the dorsal aspect of the distal phalanx in addition to widening the distance between the DP and the dorsal hoof wall [29]. This distance should be less than $18 \mathrm{~mm}$ in normal horses or less than $30 \%$ of the palmer length of the DP measured from the tip of the bone to its articulation with the navicular bone [19]. Palmar or plantar rotation of the DP away from the dorsal hoof wall confirms the diagnosis of laminitis [9, 26].

Various studies provided some parameters which define the morphometric characteristics of the DP of the foot, which can be used objectively, both to assess the anatomy of the DP and to confirm the presence and extent of degenerative change of the DP. A number of different radiological parameters are therefore required to fully document the anatomy of the foot and to evaluate fully the nature and extent of the anatomical changes present within the affected foot. It is a clinical imperative to be able to accurately detect modest change within the affected foot because recovery prospects are generally accepted to be related both to the nature and extent of the anatomical changes within the foot [10]. There are inherent inaccuracies associated with the measurement of radiological parameters and alternative parameters which can improve diagnostic accuracy are welcomed. For example, in a study by Collins et al. [6], measurement of angle subtended between the dorsal aspect of the DP and the ground line, represented an improvement on former methods of evaluating the orientation of the dorsal aspect of the DP. Likewise, if measurement accuracy cannot be fundamentally improved, then accordance between different parameters which employ various approaches to measure differently the same dislocation event to measure angular deviation between the dorsal aspect of the DP and dorsum of the hoof wall, can provide greater confidence in a diagnosis of anatomical change.

On the other hand, in a normal horse, the angle made by DPh (the solar border of the distal phalanx and the ground) varies from $2^{\circ}$ to $10^{\circ}$ [24]. In long toe/low heel conformation, this angle is different because the palmar processes of the solar border of the DP are closer to the ground compared to the cranial border [4], causing extension of the coffin joint. As the solar border of the distal phalanx is the insertion point of the DDFT, a change in its orientation, such as that seen with collapsed heels, may increase the length of the DDFT. Since the DDFT is loaded during stance by its accessory ligament [32], and as there is an approximately linear relationship between DDFT length and force [21], this change in the angle made by DPh orientation may also increase the DDFT tensile force and subsequently the force it exerts on the navicular bone. In a study, Eliashar et al. [12] hypothesised that DPh and the ground is correlated to the degree of heel collapse and that foot conformation is correlated to the compressive force exerted by the DDFT on the navicular bone.

Many published studies have been done on measurement of coffin bone in front feet $[9,13,17,19]$; while few studies have been done on hind feet [9]. Cripps and Eustace [9] measured the angles in front feet of mix breeds. These authors found that the mean angle $\mathrm{S}$ and $\mathrm{T}$ in the front feet of 22 Thoroughbred horses were 48.6 degrees and 47.6 degrees, respectively. The measurement of these parameters in our study is in close agreement with these authors $[9,20$, 31]. $\mathrm{H}$ angle in our study was -0.2 in comparison to Crips and Eustac [9] (-1) and Masoudifard et al. [20] (0.4). Cripps and Eustace [9] reported that angle $U$ 
was 43.8 degrees, while $R$ angle was 3.8 degrees. The finding of our study (U: 56.6, R: 7.2) was different than theirs and from results that were obtained by Masoudifard et al. (2014) [20] (U: 49.2, R:-0.2). In our study the amount of angle $U$ and $R$ was 56.6 and 7.2. Differences between the two studies may be related to breed or type of horses. Differences in measurement techniques may also have contributed $[9,18]$.

The measurement values of wall thickness in this study and that reported by Cripps and Eustace [9] were different. According to Cripps and Eustace [9] the mean wall thickness measurements from front feet of normal Thoroughbred horses were $16.3 \mathrm{~mm}$ in STTM. Linford et al. [19] reported that the widest thickness at the hoof wall and its soft tissue was $18 \mathrm{~mm}$. Our result in STTM was 18.1. O'Brien et al. [22] stated that increase in the hoof wall thickness and its related soft tissue to more than $20 \mathrm{~mm}$ is the first radiographic sign of laminitis. This increase is due to the inflammation of the laminae and will be seen on lateromedial radiographs almost $48 \mathrm{~h}$ to $72 \mathrm{~h}$ after laminitis start to grow. No part of the hoof wall and its related soft tissue thickness was more than $20 \mathrm{~mm}$ in the present study. It shows that none of the horses in our study had lameness and/or laminitis complications. Based on a study by Linford et al. [19] wall thickness in the normal horse is less than $30 \%$ (25-30) of PCL. Our results were $26.3 \pm 0.9,26.7 \pm$ \pm 0.75 and $27.5 \pm 0.65$ in three proximal, middle and distal regions respectively (Table 1 ). It showed that mean of this criterion was less than $30 \%$ in all cases. These findings also confirmed the health of the feet of the horses in our study. It seems that foot conformation and radiological anatomy measurements of the pure Iranian Arabian horses are in the normal range of the other breeds. There are some differences between hoof wall thickness and soft tissue measurements in this study and other studies $[9,19,20]$, which can be due to the differences in breeds, ages, hoof care, sport activities, or the nutrition of the examined horses.

Founder distance is a parameter first described by Cripps and Eustace [9]. They stated that measuring the founder distance is a diagnostic criterion in laminitis. Our measurements according to Cripps and Eustace [9] method were based on a marker with the most proximal end at the point below the coronary band, where the wall horn began to yield to moderate digital pressure. In another study the marker was positioned with the proximal end at the hairline [17].
The different position of the marker explains the differences in measurements. Cripps and Eustace [9] reported that founder distance values in front feet of 22 Thoroughbred horses were about $5.2 \pm 1.97$ $\mathrm{mm}$. In our study founder distance was about $6.2 \pm$ $\pm 0.43 \mathrm{~mm}$. This parameter in Akhal-Teke and Darehshori were $6.2 \pm 2.93$ and $5.6 \pm 1.1$, respectively $[20,31]$. The differences between left and right feet were not statistically significant $(p>0.05)$ in our and other mentioned studies. Generally, differences in founder distance (apart from the effect of marker placement) may be due to variations in limb loading, or a consequence of laminitis. However, the degree of natural variation indicates that this parameter is only of limited usefulness in the early stages of laminitis $[9,19]$.

In one study [9] it was demonstrated that while dorsopalmar obliquity did not produce errors in the measurement of $D$, they contrast with the situation that has been reported for angle $\mathrm{H}$ [16]. There was a real effect of proximo-distal obliquity on the founder distance. However, the estimated effect, $1.5 \mathrm{~mm}$ change in $D$ for every $100 \mathrm{~mm}$ change in beam height, is not likely to be of clinical importance assuming conventional radiographic technique. Nevertheless, it does emphasize the need for a standardised technique and the importance of keeping the central beam constant during a sequence of radiographs [9].

Linford et al. [19] propounded that existence of palmarocortical resorption, which causes an obvious convexity on the palmarocortical region on the lateral radiographs, is a sign for laminitis and founder. In this relation, Masoudifard et al. [20] assessed a new creation called P-angle. This criterion may be useful as an indicator of laminitis [20].

\section{CONCLUSIONS}

This study represents the first detailed evaluation of the radiological foot anatomy of the pure Iranian Arabian horse. This radiological assessment provides new baseline data for the lateromedial radiographic view of normal pure Iranian Arabian horse feet, against which objective clinical comparisons can be made. It also defines the anatomical changes that occur are associated with laminitis.

\section{Acknowledgements}

The authors would like to thank Dr. Dehghan for preparing the figures. 
This research was financially supported by a grant (No: 27/12/1393) from the Technology and Research Council of Shahid Bahonar University of Kerman, Iran.

\section{REFERENCES}

1. Balch OK, Butler D, Collier MA. Balancing the normal foot: hoof preparation, shoe fit and shoe modification in the performance horse. Equine Vet Edu. 1997; 9(3): 143-154, doi: 10.1111/j.2042-3292.1997.tb01295.x.

2. Baxter GM. Adams and Stashak's lameness in horses. 5th ed. Wiley, Philadelphia, USA 2002: 645-664.

3. Bushe T, Turner T, Poulos P, et al. The effect of hoof angle on coffin, pastern, and fetlock joint angles. Proc Am Ass: Equine Pract. 1987; 33: 729-737.

4. Butler JA, Colles CM, Dyson SJ. Foot, pastern and fetlock. In: Clinical Radiology of the Horse. 2nd ed. Blackwell, Oxford, UK 2000: 27-130.

5. Colles CM. Interpreting radiographs 1: the foot. Equine Vet J. 1983; 15(4): 297-303, indexed in Pubmed: 6641676.

6. Collins SN, Dyson SJ, Murray RC, et al. Radiological anatomy of the donkey's foot: objective characterisation of the normal and laminitic donkey foot. Equine Vet J. 2011; 43(4): 478-486, doi: 10.1111/j.2042-3306.2010.00312.x, indexed in Pubmed: 21631583.

7. Collins SN, van Eps AW, Pollitt CC, et al. The lamellar wedge. Vet Clin North Am Equine Pract. 2010; 26(1): 179-195, doi: 10.1016/j.cveq.2010.01.004, indexed in Pubmed: 20381746.

8. Collins SN, Wealleans H, Hopegood L, Latham RJ, Newlyn HA, Reilly JD. Current studies on the donkey hoof. Medicine and Surgery of the Donkey. Proceedings 2nd CPD Course, Glasgow 2002: 1-15.

9. Cripps PJ, Eustace RA. Radiological measurements from the feet of normal horses with relevance to laminitis. Equine Vet J. 1999; 31(5): 427-432, indexed in Pubmed: 10505960.

10. Cripps PJ, Eustace RA. Factors involved in the prognosis of equine laminitis in the UK. Equine Vet J. 1999; 31(5): 433-442, indexed in Pubmed: 10505961.

11. Eliashar E, McGuigan MP, Rogers KA, et al. A comparison of three horseshoeing styles on the kinetics of breakover in sound horses. Equine Vet J. 2002; 34(2): 184-190, indexed in Pubmed: 11902761.

12. Eliashar E, McGuigan MP, Wilson AM. Relationship of foot conformation and force applied to the navicular bone of sound horses at the trot. Equine Vet J. 2004; 36(5): 431-435, indexed in Pubmed: 15253085.

13. Eustace RA, Cripps PJ. Factors involved in the prognosis of equine laminitis in the UK. Equine Vet J. 1999; 31(5): 433-442, indexed in Pubmed: 10505961.

14. Herthel D, Hood DM. Clinical presentation, diagnosis, and prognosis of chronic laminitis. Vet Clin North Am Equine Pract. 1999; 15(2): 375-94, vii, indexed in Pubmed: 10472118.

15. Hood DM, Taylor D, Wagner IP. Effects of ground surface deformability, trimming, and shoeing on quasistatic hoof loading patterns in horses. Am J Vet Res. 2001; 62(6): 895-900, indexed in Pubmed: 11400847.

16. Koblik PD. O'Brien TR, Coyne CP Effect of dorsopalmar projection obliquity on radiographic measurement 01 distal phalangeal rotation angle in horses with laminitis. J Am Vet Med Ass. 1988; 192: 346-349.
17. Kummer M, Geyer H, Imboden I, et al. The effect of hoof trimming on radiographic measurements of the front feet of normal Warmblood horses. Vet J. 2006; 172(1): 58-66, doi: 10.1016/j.tvjl.2005.03.008, indexed in Pubmed: 16772132.

18. Kummer M, Lischer C, Ohlerth S, et al. Evaluation of a standardised radiographic technique of the equine hoof. Schweiz Arch Tierheilkd. 2004; 146(11): 507-514, doi: 10.1024/00367281.146.11.507, indexed in Pubmed: 15581285.

19. Linford RL, O'Brien TR, Trout DR. Qualitative and morphometric radiographic findings in the distal phalanx and digital soft tissues of sound thoroughbred racehorses. Am J Vet Res. 1993; 54(1): 38-51, indexed in Pubmed: 8427471.

20. Masoudifard M, Vajhi AR, Mansouri Sh, et al. Radiographic measurements of front feet of the sound Akhal-Teke horses. IJVM. 2014; 8(1): 21-25.

21. McGuigan MP, Wilson AM. The effect of gait and digital flexor muscle activation on limb compliance in the forelimb of the horse Equus caballus. J Exp Biol. 2003; 206(Pt 8): 1325-1336, indexed in Pubmed: 12624168.

22. O'Brien T, Baker TA, Brounts SH, et al. Detection of articular pathology of the distal aspect of the third metacarpal bone in thoroughbred racehorses: comparison of radiography, computed tomography and magnetic resonance imaging. Vet Surg. 2011; 40(8): 942-951, doi: 10.1111/j.1532-950X.2011.00881.x, indexed in Pubmed: 22092025.

23. O'Grady SE, Poupard DA. Physiological horseshoeing: an overview. Equine Vet Educ. 2010; 13(6): 330-334, doi: 10.1111/j.2042-3292.2001.tb00123.x.

24. Parks AH. The foot and shoeing. In: Diagnosis and management of lameness in the horse. Saunders, Philadelphia, USA 2003: 252-275.

25. Parks AH, Mair TS. Laminitis: A call for unified terminology. Equine Vet Educ. 2009; 21(2): 102-106, doi: 10.2746/095777309x403673.

26. Redden RF. Hoof capsule distortion: understanding the mechanisms as a basis for rational management. Vet Clin North Am Equine Pract. 2003; 19(2): 443-462, indexed in Pubmed: 14575168.

27. Reilly JD. The donkey's foot and its care. In: The Professional Handbook of the Donkey. 2nd ed. Whitter Books, London, UK 1997: 71-93.

28. Rendano VT, Grant B. The equine third phalanx: its radiographic appearance. J Am Vet Radiol. 1978; 19: 125-135.

29. Stashak TS. Laminitis. In: Stashak TD. eds. Adams lameness in horses. 5th Ed. Baltimore, USA 2002; 645-664.

30. Tacchio G, Davies HMS, Morgante M, et al. A radiographic technique to assess the longitudinal balance in front hooves. Equine Vet J Suppl. 2002(34): 368-372, doi: 10.1111/j.2042-3306.2002.tb05450.x, indexed in Pubmed: 12405718.

31. Vali R. Some radiological measurements from the front feet of sound Dareh-Shori horses with relevance to laminitis and founder. Tren Life Sci. 2014; 3(4): 238-243.

32. Wilson AM, McGuigan MP, Fouracre $L$, et al. The force and contact stress on the navicular bone during trot locomotion in sound horses and horses with navicular disease. Equine Vet J. 2001; 33(2): 159-165, indexed in Pubmed: 11266065.

33. Wright IM, Douglas J. Biomechanical considerations in the treatment of navicular disease. Vet Rec. 1993; 133(5): 109-114, indexed in Pubmed:8212500. 